resins containing chelating groups, and a study of factors determining the semi-permeability of poly (vinyl alcohol) films in non-aqueous systems has shown that membranes of low permeability can be used to determine the molecular weights of simple compounds of known structure; work on the development of membranes for use in aqueous systems has commenced.

Besides the work already noted, the Microbiology Group continued its fundamental studies of sulphatereducing bacteria, particularly their metabolism, and the continuous process for bacterial sulphate reduction, and started some studies of the bacterial oxidation of aromatic compounds, particularly the microbiological breakdown of phthalate, a process of industrial importance in the disposal of effuents.

\section{THE ICE AGES AND PAST VARIATIONS OF THE EARTH'S CLIMATE}

$\mathrm{D}$

URING the past sixteen years, Dr. E. J. Öpik has written extensively on climatic changes in a number of publications, and in Contribution No. 9 of Armagh Observatory, entitled "A Climatological and Astronomical Interpretation of the Ice Ages and of the Past Variations of Terrestrial Climate"*, he has written a paper which largely embodies the main points in his studies.

As might be expected, Dr. Öpik rejects the old astronomical theories of the fluctuations of climatethe changes in the obliquity of the ecliptic and the eccentricity of the earth's orbit. About half a century ago these were shown to be utterly inadequate to account for glaciations and warm interglacial climates, but from time to time they have been revived. Simpson's theory of the ice ages, which was advocated a quarter of a century ago-that they are caused primarily by an increase in solar radiation which in turn leads to a rise of the mean global temperature and an increase of the absolute moisture content of the atmosphere, followed by more precipitation in the form of snow in the polar regions and an advance of glaciers-is dismissed with very little criticism. It is pointed out that there is an absurdity in the theory which postulates the melting of the glaciers and the retreat of the ice when the greater heat takes control, because both the advance and the retreat of the glaciers are explained by the same cause. In addition, climatological and other evidence points to the conclusion that the glaciers of Greenland retreated during the past century, in close response to the increased global temperature.

Dr. Öpik maintains that an interpretation of climatic changes cannot be made without a clear quantitative understanding of the heat balance of the earth, and he develops a method of quantitative analysis of the climatic heat balance, based on the equation $Q=I+E$. In this, $Q, I$ and $E$ represent respectively the net radiation to space, the net insolation or the absorbed solar radiation, and the heat supplied by other sources; the last-named includes convective interchanges with other parts of the earth's surface, such as atmospheric and oceanic

* Contributions from the Armagh Observatory; No. 9: A Climatological and Astronomical Interpretation of the Ice Ages and of the tributed by Blackwell Scientiflc Publications, Ltd., Oxford, 1953). 10s. $6 d$. net. currents, or released from that stored in the soil, the water or the atmosphere. On this basis and with certain further assumptions, standard mean radiation curves, in dependence on the mean surface temperature, are calculated for summer and winter as well as for clear and cloudy sky, and the results are given in the paper. 'Two sections, comprising twenty pages, are devoted to "Variations of Solar Luminosity" and "The Mechanism of Solar Long-Term Variability" and contain references to Öpik's work on these problems during the past fifteen years or more. Regarding the latter section, it appears that a temporary increase of the energy production near the sun's centre will lead to a decrease of solar radiation and to an ice age if the decrease is deep enough. A qualitative picture is sketched of the way in which repeated disturbances in the interior of a dwarf star like the sun can be produced, and it is just possible that here may be an explanation of the mechanism by which major ice ages were recurrent phenomena of a periodicity of about 240 million vears. Of course, there is necessarily a considerable amount of speculation in all this, and it is very difficult to make many definite deductions in such matters.

Towards the end of the paper, under "The Prob. lems of Pre-Tertiary Climate", Dr. Öpik confirms his views expressed in 1938 that, although Wegner's theory of continental drift, postulating a corresponding displacement in latitude, cannot explain the last ice age, nevertheless there can be little doubt about the reality of large-scale horizontal displacements (Alpine foldings) in the earth's crust. The opinion is expressed that even if the strange phenomena of Carbo-Permian glaciation can be partly explained by continental drift (and this glaciation is an inducement. to regard Wegner's theory favourably), this explana. tion completely fails for the earlier Cambrian glaciation.

\section{WINCHESTER COLLEGE NATURAL HISTORY SOCIETY}

T $\mathrm{T}$ is regrettable that the reports of the Winchester College Natural History Society can be published only once every three years owing to increased costs of printing, etc., for the report before us (1950-53) is well produced and makes very encouraging reading. However, duplicated summaries of observations on birds, insects and plants are issued every year.

The Society itself is very active, and the report reveals a variety of interests from general field observations to more specialized studies. Three specialized sections of the Society have now been formed-birds, insects and plants-and others may follow.

The report opens with an account by the warden, J. A. L. Myres, of the Viscount Grey Nature Reserve, "Fallodon", which is a part of Watermeads, a piece of land belonging to the College. It is quite clear that enthusiastic boys of the College have done much to render this nature reserve a really valuable asset since the War, during which its upkeep proved impossible.

P. J. Chadder gives an excellent account of the birds' nests (fifteen nests of seven different species) he examined in Fallodon during 1953. This is followed by a numerical analysis of the seasonal changes in birds in that reserve by D. E. D. Campbell. 